Sander, Julia; Schmiedek, Florian; Brose, Annette; Wagner, Gert G.; Specht, Jule

\title{
Long-term effects of an extensive cognitive training on personality development
}

formal und inhaltlich überarbeitete Version der Originalveröffentlichung in:

formally and content revised edition of the original source in:

Journal of personality 85 (2017) 4, S. 454-463, 10.1111/jopy. 12252

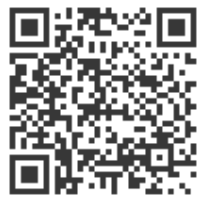

Bitte verwenden Sie in der Quellenangabe folgende URN oder DOI /

Please use the following URN or DOI for reference:

urn:nbn:de:0111-dipfdocs-176691

$10.25657 / 02: 17669$

https://nbn-resolving.org/urn:nbn:de:0111-dipfdocs-176691

https://doi.org/10.25657/02:17669

\section{Nutzungsbedingungen}

Gewährt wird ein nicht exklusives, nicht übertragbares, persönliches und beschränktes Recht auf Nutzung dieses Dokuments. Dieses Dokument is ausschließlich für den persönlichen, nicht-kommerziellen Gebrauch bestimmt. Die Nutzung stellt keine Übertragung des Eigentumsrechts an diesem Dokument dar und gilt vorbehaltlich der folgenden Einschränkungen: Auf sâmtlichen Kopien dieses Dokuments müssen alle Urheberrechtshinweise und sonstigen Hinweise auf gesetzlichen Schutz beibehalten werden. Sie dürfen dieses Dokument nicht in irgendeiner Weise abändern, noch dürfen Sie dieses Dokument für öffentliche oder kommerzielle Zwecke vervielfältigen, öffentlich ausstellen, aufführen, vertreiben oder anderweitig nutzen.

Mit der Verwendung dieses Dokuments erkennen Sie die Nutzungsbedingungen an.

\section{Terms of use}

We grant a non-exclusive, non-transferable, individual and limited right to using this document.

This document is solely intended for your personal, non-commercial use. Use of this document does not include any transfer of property rights and it is conditional to the following limitations: All of the copies of this documents must retain all copyright information and other information regarding legal protection. You are not allowed to alter this document in any way, to copy it for public or commercial purposes, to exhibit the document in public, to perform, distribute or otherwise use the document in public.

By using this particular document, you accept the above-stated conditions of use.

\section{Kontakt / Contact:}

DIPF | Leibniz-Institut für

Bildungsforschung und Bildungsinformation

Frankfurter Forschungsbibliothek

publikationen@dipf.de

www.dipfdocs.de

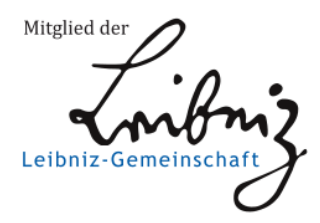


This is the peer reviewed version of the following article:

Sander, J., Schmiedek, F., Brose, A., Wagner, G. G., \& Specht, J. (2017). Long-Term Effects of an Extensive Cognitive Training on

Personality Development. Journal of personality, 85(4), 454-463., which has been published in final form at https://doi.org/10.1111/jopy.12252 . This article may be used for non-commercial purposes in accordance with Wiley Terms and Conditions for Self-Archiving 
Long-Term Effects of an Extensive Cognitive Training on Personality Development Julia Sander ${ }^{1,2,3}$, Florian Schmiedek ${ }^{1,4,6}$, Annette Brose ${ }^{1,5}$, Gert G. Wagner ${ }^{1,6,7}$ \& Jule Specht ${ }^{1,2}$

${ }^{1}$ German Institute for Economic Research (DIW Berlin), Berlin, Germany ${ }^{2}$ Freie Universität Berlin, Berlin, Germany

${ }^{3}$ International Max Planck Research School on the Life Course, Berlin, Germany ${ }^{4}$ German Institute for International Educational Research (DIPF), Frankfurt am Main, Germany

${ }^{5}$ Humboldt-Universität zu Berlin, Berlin, Germany

${ }^{6}$ Max Planck Institute for Human Development, Berlin, Germany

${ }^{7}$ Berlin University of Technolgy, Berlin, Germany 


\section{Author Note}

Julia Sander, Socio-Economic Panel Study, German Institute for Economic Research (DIW Berlin), Berlin, Germany, Department of Psychology, Freie Universität Berlin, Berlin, Germany, and International Max Planck Research School on the Life Course, Berlin, Germany; Florian Schmiedek, German Institute for International Educational Research (DIPF), Frankfurt am Main, Germany, Max Planck Institute for Human Development, Berlin, Germany, and German Institute for Economic Research (DIW Berlin), Berlin, Germany; Annette Brose, Department of Psychology, Humboldt-Universität zu Berlin, Germany, and German Institute for Economic Research (DIW Berlin), Berlin, Germany; Gert G. Wagner, German Institute for Economic Research (DIW Berlin), Berlin, Germany, Max Planck Institute for Human Development, Berlin, Germany, and Berlin University of Technology, Berlin, Germany; Jule Specht, Department of Psychology, Freie Universität Berlin, Berlin, Germany, and German Institute for Economic Research (DIW Berlin), Berlin, Germany.

During the work on her dissertation, Julia Sander is a pre-doctoral fellow of the International Max Planck Research School on the Life Course (LIFE, www.imprslife.mpg.de). Her dissertation work is also supported by a stipend from the German Institute for Economic Research (DIW Berlin), Berlin, Germany.

Correspondence concerning this article should be addressed to Julia Sander, SocioEconomic Panel Study, German Institute for Economic Research (DIW Berlin), Mohrenstraße 58, 10117 Berlin, Germany, E-mail: jsander@diw.de, or to Jule Specht, Department of Psychology, Freie Universität Berlin, Habelschwerdter Allee 45, 14195 Berlin, Germany, Email: jule.specht@fu-berlin.de 


\begin{abstract}
Objective: Previous research found that cognitive training increases the Big Five personality trait openness to experience during and some weeks after the intervention. The present study investigated whether long-term changes happen in openness to experience and other personality traits after an extensive cognitive training of memory and perceptual speed.

Method: Intervention group consisted of 204 adults (20-31 years and 65-80 years, $50 \%$ female), who received daily one-hour cognitive training sessions for about 100 days. The control group consisted of 86 adults (21-29 years and $65-82$ years, $51 \%$ female), who received no cognitive training. All participants answered the NEO Five-Factor Inventory before and two years after the cognitive training. Latent change models were applied that controlled for age group (young vs. old) and gender.
\end{abstract}

Results: In the long-run the cognitive training did not affect changes in any facet of openness to experience. This was true for young and old participants as well as for men and women. Instead, the cognitive training lowered the general increase of conscientiousness.

Conclusion: Even an extensive cognitive training on memory and perceptual speed does not serve as a sufficient intervention for enduring changes in openness to experiences or one of its facets.

Keywords: personality development, openness to experience, cognitive training, intervention, Big Five personality traits 


\section{Long-Term Effects of an Extensive Cognitive Training on Personality Development}

Modern societies focus on self-optimization. Not only the outward appearance is captured by the desire for eternal youth, it is en vogue to test ones brain age and to do brain jogging in order to keep one's mind in shape. In recent years, brain games were a growing market: Many brain training games and apps popped up with promising names like, e.g. "Neuron Gym" (Edlogiq, 2014), "NiceIQ" (Depthlink Inc., 2015), or "Fit Brains" (Vivity Labs, 2015). Marketing strategies fuel the hype of self-improvement, suggesting that cognitive trainings have a positive impact, not only on memory, attention and reaction speed but also on an "increase of [...] creativity" (Edlogiq, 2014, Neuron Gym), an indicator for openness to experience, or on a "more positive mood" (Depthlink Inc., 2015, NiceIQ). Positive emotionality again is an indicator for the personality trait of extraversion (John, Naumann, \& Soto, 2008).

Indeed, there are some first findings showing effects of cognitive trainings on personality traits (Jackson, Hill, Payne, Roberts, \& Stine-Morrow, 2012; see also DittmannKohli, Lachmann, Kliegl, \& Baltes, 1991). This applies particularly to openness to experience, a personality trait that is associated with creative thinking, enjoyment of intellectual pursuit, seeking out new challenging activities and cognitive flexibility (Ackerman \& Heggestad, 1997; McCrae \& Sutin, 2008). In an experimental study, Jackson and colleagues (2012) found that an adaptive cognitive training aimed at improving the fluid cognitive ability of inductive reasoning led elderly people to increase in openness to experiences during the intervention and the following weeks. However, long-term effects on personality remain unknown to date. Furthermore, it is unclear which cognitive trainings impact the development of openness and what potential boundary conditions are. 


\section{How Changeable is Personality?}

Is it reasonable to speculate about personality trait change even though personality is defined as being relatively enduring? Yes, it is! According to lifespan development theory (Baltes, 1997) personality trait changes are possible to happen even in middle and old age (see also Baltes, Lindenberger, \& Staudinger, 2006). Empirical findings support the conception of lifelong personality development (see Roberts \& DelVecchio, 2000; Roberts, Walton, \& Viechtbauer, 2006), pointing to a development towards greater maturity (i.e., increases in emotional stability, agreeableness, and conscientiousness) across the lifespan. Recent studies reveal that rank-order stability of personality traits follow an inverted U-shaped function reaching a peak between the ages of 40 and 60 and decreasing afterwards with a level of instability in old age comparable to young adulthood (Lucas \& Donnellan, 2011; Specht, Egloff, \& Schmukle, 2011). Also, personality types are highly consistent across gender, age, and time but there are meaningful changes in type membership across all of adulthood (Specht, Luhmann, \& Geiser, 2014).

Even though lifelong personality trait change is widely accepted, the underlying mechanisms and possibilities to intervene are currently discussed (Specht, Bleidorn et al., 2014). As assumed by sociogenomic theory, environmental changes might impact personality states which, in the long run, might lead to changes in deep-seated personality traits (Roberts \& Jackson, 2008). According to Hudson and Fraley (2015), environmental changes serve as consistent pressures for new patterns of thoughts, feelings, behaviors and a modified selfview, which is a precondition for enduring personality trait changes. Thus, interventions on personality built on the idea of bottom-up processes, where personality traits change through repeated behavioral activation (Chapman, Hampson, \& Clarkin, 2014; Jackson, et al., 2012; Magidson, Roberts, Collado-Rodriguez, \& Lejuez, 2012).

Engaging in an extensive cognitive training that requires mental flexibility and is cognitively stimulating may enhance the willingness to seek for new (cognitive) challenges in 
general. This generalization in turn would equate to changes at a higher personality trait-level of openness to experience. So far, there is no empirical evidence for such a generalized longterm effect on personality from an intense cognitive training aimed at improving memory and perceptual speed.

\section{The Current Study}

Here, we use data of a cognitive training that was designed to monitor and improve cognitive abilities in episodic memory, working memory, and perceptual speed over 100 daily one hour sessions. Openness to experience and all of the other Big Five personality traits (emotional stability, extraversion, agreeableness, and conscientiousness), were assessed right before the cognitive training intervention and two years after. This enabled us to investigate whether an extensive cognitive training beyond inductive reasoning can lead to long-term changes in openness to experience. Effects of the training on other personality traits as well as interactions with age and gender were explored.

\section{Method}

\section{Participants}

A total of 290 participants $(50.7 \%$ female $)$ were included in the analyses. The intervention group ( $N=204$ at pretest) consisted of two age groups. The young age group ( $N$ $=101,51.5 \%$ female $)$, that completed an average of 101 training sessions $(S D=2.6$ sessions, range: $87-109$ sessions) ranged in age from 20 to 31 years $(M=25.6$ years; $S D=2.7$ years $)$. Participants in this young-intervention group finished an average of 16.1 years of education $(S D=3.2$ years of education). The old age group $(N=103,50.5 \%$ female), who also completed an average of 101 training sessions ( $S D=2.7$ sessions, range: 90 - 106 sessions) ranged in age from 65 to 80 years $(M=71.3$ years; $S D=4.1$ years). Participants in this old- 
intervention group finished an average of 13.6 years of education $(S D=3.6$ years of education).

Participants in the no-training control group $(N=86)$ also consisted of two age groups. The young age group $(N=45,51.1 \%$ female), ranged in age from 21 to 29 years $(M=25.2$ years; $S D=2.5$ years). Young control group participants finished an average of 15.7 years of education $(S D=2.7$ years of education). The old age group $(N=41,51.2 \%$ female $)$ ranged in age from 65 to 82 years $(M=70.5$ years; $S D=3.9$ years $)$. Old control group participants finished an average of 13.0 years of education $(S D=3.9$ years of education).

Intervention and control groups did not differ on age, initial cognitive status, and education (see Schmiedek, Lövdén, \& Lindenberger, 2010). Also, there were no significant mean differences in the Big Five personality traits or facets between the intervention and control group before the cognitive training (all $p \mathrm{~s}>.05 ; d$ ranging from -.11 to .16 ).

The attrition rate for participants who attended the pretesting and had entered the intervention was low $(93.2 \%$ of the initial intervention group completed the cognitive training phase; for details on dropout by study phase and reasons for dropping out, see Schmiedek et al., 2010). At 2-year follow-up $71(82.6 \%)$ members of control group and 167 (81.9\%) members of intervention group participated in personality assessment again. Those who did not attend the follow-up personality assessment after two years (dropouts, 56\% female) more often were in the young age group than in the old age group $\left(\chi^{2}=5.7, p=.02\right)$. Continuers and dropouts did not differ on any of the investigated personality facets or traits at pretest; neither did they differ in education.

\section{Procedure}

Participants come from the COGITO study that was originally designed to (1) investigate day-to-day fluctuations in cognitive performance and (2) to examine transfer effects of trained cognitive tasks on non-trained cognitive tasks. Participants completed 
perceptual speed, episodic memory, and working memory tasks using verbal, numerical, and figural-spatial task material, for example two-choice reaction tasks, memorizing tasks, and different working memory paradigms in the lab. In total, participants practiced 12 different basic cognitive tasks for 1 to 1.5 hours per training session (see Schmiedek, Bauer, Lövdén, Brose, \& Lindenberger, 2010; Schmiedek, Lövdén, and Lindenberger, 2010).

Individuals were recruited via different kinds of advertisement, such as newspaper advertisements, word-of-mouth recommendation, and distribution of flyers with no further information on financial remuneration mentioned at this point. At the end of the study, participants in the intervention group were paid between 1,450 and 1,950 EUR, depending on a bonus for participation frequency. Participants in the control group were paid 460 EUR.

Assignment to groups was not completely random (i.e., the control group was filled after filling the intervention group), but the resulting samples were well comparable (see sample description in Participants paragraph and Schmiedek, Lövdén, and Lindenberger, 2010). For details of the study procedure, please see Figure 1.

Difficulty level of the cognitive tasks was adapted to pretest performance once before the training phase started. Reliable positive transfer of cognitive training was found on cognitive abilities, especially on reasoning and episodic memory, in the young age group, but not on other cognitive abilities and not in the old age group (Schmiedek, Lövdén, \& Lindenberger, 2010; Schmiedek, Lövdén, \& Lindenberger, 2014).

\section{Measures}

The Big Five personality traits were assessed with 60 items of the NEO-PI-R Inventory (NEO-FFI; Costa \& McCrae, 1992). Participants rated the items on a 5 point scale ranging from (0) strongly disagree to (4) strongly agree. Evidence on convergent and discriminant validity of the NEO-FFI is given in Costa and McCrae (1992). In order to monitor effects of cognitive training on specific facets of personality and to enhance the 
precision of findings, analyses were made using Saucier's subscales of the NEO-FFI (cf. Saucier, 1998; see also Chapman, 2007). Following Saucier (1998), two items of the openness to experience scale were left out ("I often try out new and foreign food"; "I rarely notice moods or feelings that are evoked by different environments"). Further, we excluded two items because of unexpected loadings (i.e., negative) on their personality trait in our sample at post-test: "I live a hectic life" (subscale: activity, extraversion factor loading $=-0.10$ ) and "I believe that we should take heed of the views of our religious authorities at ethical decisions“(subscale: unconventionality, openness factor loading $=-0.02)^{1}$.

Descriptive statistics and internal consistencies of personality traits and Saucier's subscales in the current sample are listed in Table 1. Given the small number of items per cluster, the reliabilities for some item clusters were moderate, ranging from Cronbach's alpha .55 to .85 , with two exceptions in openness facets, in particular unconventionality $($ Cronbach's alpha $=.37)$ and aesthetic interests $($ Cronbach's alpha $=.47)$. Nevertheless, alpha reliabilities in the current sample are within the range of previous studies using the same item clusters (Allemand, Hill, \& Lehmann, 2015; Chapman, 2007).

\section{Statistical Models}

Structural equation modeling was used in the current study to investigate changes at the construct level of latent factors representing the personality dimensions free of measurement error. Latent change score models (LCSM; McArdle, 2009) were estimated with Mplus Version 7.3 (see Muthén \& Muthén, 1998-2012). To include the greatest possible number of observations we used the full information maximum likelihood (FIML) approach, which is a model-based approach to missing data in dependent variables (Enders \& Bandalos, 2001). Evaluation of model fit was based on the Comparative fit index (CFI), the Root mean square error of approximation (RMSEA), and the Standardized root mean square residual 
(SRMR). A CFI above .90 and an RMSEA and SRMR below .08 indicate an acceptable model fit to data (Hu \& Bentler, 1998; Marsh, Hau, \& Grayson, 2005).

In order to test the assumption of measurement invariance across time, measurement invariance models were evaluated (cf. Marsh, Nagengast, \& Morin, 2013; van de Schoot, Lugtig, \& Hox, 2012). To examine the effects of age group on personality change due to cognitive training, we compared model fit indices of models where the slopes were freely estimated for all four groups (young control, young intervention, old control, and old intervention group) with models in which the slopes were set equal across groups. Comparisons were conducted using $\chi^{2}$-difference tests for every personality facet.

There were two latent change models for each personality trait and facet. First, we modeled change over time in the control group to examine general developmental trends. Second, we estimated models including covariates to analyze effects of cognitive training $(0=$ control group; 1 = intervention group $)$, age group $(0=$ young; $1=$ old $)$ and gender $(0=$ female; $1=$ male) on the latent intercept and slope factors. Factor loadings on the intercept factor were fixed to 1. Factor loadings on the slope factor were fixed to 0 at the first measurement point, before the training, and to 1 at the second measurement point, two years after the training. A significant effect of a covariate on the intercept factor reflects individual differences on the respective personality facet before the cognitive training. A significant influence of a covariate on the slope means that individuals with different values on this covariate differ in their personality trait change over time.

\section{Results}

First, we present the findings on measurement invariance across time, followed by multiple group models that test interaction effects of age group and cognitive training on changes in personality facets. Afterwards, we report on the latent change models including the effects of cognitive training, and age group on intercept of personality traits and facets. The 
effect of gender was modeled as an additional covariate with potential effects on initial personality (e.g. Bleidorn, Kandler, Riemann, Angleitner, \& Spinath, 2009). Subsequently, we focus on the latent change models that estimated changes in personality facets in the control group over time and we report effects of cognitive training, age group, and gender on slope of personality traits and facets.

Strong measurement invariance was established in all models, meaning that factor loadings and item intercepts within all personality traits and facets remained invariant across time. Except for two personality subscales, all strong measurement invariance models fit the data well $(\mathrm{CFI}>.94$, RMSEA $<.08$, SRMR $<.06)$. There was a slightly worse, but still acceptable, model fit for the measurement invariance models of the personality facet dependability (conscientiousness; CFI $=.91$, RMSEA $=.10$, SRMR $=.07$ ), and negative affect (emotional stability; $\mathrm{CFI}=.88, \mathrm{RMSEA}=.08, \mathrm{SRMR}=.07)$. Personality traits were modeled as second-order factors whose indictors were the respective personality facets. Strong measurement invariance models for personality traits at the factor level show moderate model fit $(\mathrm{CFI}>.87, \mathrm{RMSEA}<.07, \mathrm{SRMR}=.08)$.

There were no interaction effects of age group and cognitive training on changes in personality facets: Multiple group models show that for all investigated personality facets, the latent change models did not fit significantly worse when slopes were constrained to be equal across groups than when estimated freely (this was true for the following four groups: young control, young intervention, old control, and old intervention). Thus, cognitive training effects on personality trait change can be interpreted as being independent from age group.

Model fit indices for the latent change models on personality trait level in the control group ranged from $\mathrm{CFI}=0.78$ to $0.86, \mathrm{RMSEA}=0.07$ to 0.08 and $\mathrm{SRMR}=0.09$ to 0.12 . Except for both agreeableness facets, all model fit indices for latent change on personality facets in control group indicated good fit, with CFI $>.93$, RMSEA $<.08$, SRMR $<.09$. Model fit indices for the latent change model of nonantagonistic orientation (agreeableness) in the 
control group were $\mathrm{CFI}=0.92, \mathrm{RMSEA}=0.11$, and $\mathrm{SRMR}=0.05$. Model fit indices for the latent change model of prosocial orientation (agreeableness) in the control group were CFI = $0.88, \mathrm{RMSEA}=0.11$ and $\mathrm{SRMR}=0.09$

Of primary interest were the latent change models with covariates. Table 2 includes all model fit indices and intercepts of these models. There was no effect of group membership (intervention or control) concerning latent differences on personality traits or facets before the cognitive training (intercepts). However, there were effects of age on personality before the intervention: With regard to openness to experience, older individuals were less intellectually interested and less unconventional but more aesthetically interested than younger participants. But, because of effects in opposite directions on facet-level no age group effect on trait level in openness to experience was apparent. There were no age differences in trait of extraversion or any of its facets. Further, older participants were more emotionally stable and agreeable than younger participants on trait-level and regarding all respective facets. Moreover, older participants were significantly higher in conscientiousness on trait-level, whereas on facetlevel they were only more dependable and orderly than the younger participants, but there was no age difference in the facet of goal striving. With regard to gender, men had higher intellectual interests (openness to experience facet), and were less dependable and orderly (conscientiousness facets) compared to women before the training. Men showed higher values on trait-level of emotional stability than women but not on facet-level. Further, men were less agreeable on trait-level and all agreeable facets.

In addition to change over time in the control group the impact of cognitive training, age group, and gender on changes in personality facets after two years (slopes) can be found in Table 3. On the trait level only extraversion, emotional stability and conscientiousness increased over two years in control group with no cognitive training. Yet, for all of the Big Five personality traits, one or more personality facets changed over time in the control group. Thus, there was a general increase over time in intellectual interest (openness to experience), 
sociability (extraversion), self-reproach (inverse coded; emotional stability), dependability and orderliness (both conscientiousness), as well as in prosocial orientation (agreeableness).

Contrary to our expectations, openness to experience did not change in the long-term in reaction to this extensive training. Also, there was no long-term effect of this cognitive training on changes in any other personality trait or facet despite one exception: Individuals who did the cognitive training showed less increase over time in the conscientiousness trait, particularly in dependability and orderliness facets. However, dependability still significantly increased in the intervention group $\left(M_{\text {Slope }}=0.351, p<.001\right)^{2}$, even though to a smaller degree than in the control group. Orderliness remained stable in the intervention group $\left(M_{\text {Slope }}\right.$ $=0.044, p>.05)^{2}$ whereas this facet increased in the control group (see Table 3). Furthermore, being old raised the likelihood to decline in unconventionality (a facet of openness to experience) over time, irrespective of whether individuals had a training or not. In addition, being male raised the likelihood to decline over two years in aesthetic interests (a facet of openness to experience) and raised the likelihood to decrease in self-reproach (a facet of emotional stability that was inverse coded).

\section{Discussion}

Mean-level increase of conscientiousness, emotional stability, extraversion and facets of agreeableness and openness, evidenced in our control group is in line with the maturation principle of personality development and growth over time (for reviews see, Roberts, Walton, \& Viechtbauer, 2006; Roberts, Wood, \& Caspi, 2008; Specht, Bleidorn, et al., 2014). With regard to the impact of a cognitive training on personality change two years after intervention: Our analysis revealed that, despite of the successful cognitive transfer of training on reasoning and episodic memory in our sample (Schmiedek, Lövdén, \& Lindenberger, 2010; Schmiedek et al., 2014), such a highly extensive cognitive training did not lead to long-term increases in openness to experience in young or old, male or female individuals. Two years after the 
cognitive training, no "side-effects" on openness to experience were found, even though the cognitive training was part of everyday life, including daily one-hour sessions for a period of a hundred days. Due to repeating cognitive challenges during the training phase, we expected openness to experience to change in line with personality state changes. Changes in personality states might have been apparent but contrary to predictions of sociogenomic theory (Roberts \& Jackson, 2008), no bottom-up transfer on the personality facets of openness to experience, that is, intellectual interests, unconventionality, or aesthetical interests, persisted in the long run.

Cognitive trainings are designed to change cognitive abilities in the first place. A lack of impact on the development of openness to experience is therefore not necessarily a drawback of the cognitive training. However, it raises awareness to the fact that enduring behavior change with regard to intellectual activity does not necessarily lead to changes in personality, in particular, to intellectual interests and other facets of openness to experience.

Former studies found effects of cognitive trainings on personality development (e.g.: Jackson et al., 2012). Our extensive cognitive training study now provides information of boundary conditions of such trainings. One of these boundary conditions might be the type of cognitive task trained. The present sample practiced working memory, episodic memory, and perceptual speed. In their meta-analysis, Ackerman and Heggestad (1997) show that openness is more strongly related to crystallized abilities (e.g., knowledge) but less so to fluid intelligence, learning, memory, and speed, which were in the focus of the training here. Hence, our findings might imply that training aiming to stimulate increases in openness to experience should focus on tasks related to crystallized abilities (e.g., Sudoku, puzzles, crosswords; Jackson et al., 2012).

Another boundary condition might be the duration of training effects on personality. Our cognitive intervention might either have produced short-term changes in openness to experience that faded over two years or no changes in openness at all. Most importantly, the 
cognitive intervention had no lasting impact on trait measures and thus, true personality change did not take place.

Additionally, ongoing tailoring of task difficulty to progress might be another potential boundary condition and worth further investigation. The difficulty level of tasks was adapted only once, at the pretests, and was not tailored again in the cognitive training phase. Maybe dynamic adaption of task difficulty might be necessary to continuously provide new challenges that reinforce a person's interest and thus openness to experience.

Also, a strong motivation to treat one's characteristics might be a promising factor when investigating personality trait change through cognitive interventions (see Hudson \& Fraley, 2015; Peters, 2015). We cannot rule out that a low motivation to change in personality characteristics might have prevented transfer from cognitive training to personality trait change in our sample.

Instead of increasing openness to experience, there were two unexpected effects on the facets of conscientiousness. Individuals who took part in the training increased less in dependability and orderliness compared to those without a cognitive training. However, dependability still increased, even though to a smaller degree. Orderliness remained static in the intervention group. This rather negative effect of cognitive training on conscientiousness facets was particularly surprising because previous research stated that changes in conscientiousness could not be attributable to the cognitive training (Jackson et al., 2012). Certainly, these unexpected findings await replication before drawing conclusions.

\section{Limitations and Future Directions}

Despite several strengths, such as the longitudinal investigation of a diverse sample and the quasi-experimental design with an extensive cognitive training, there are also some limitations in the present study. First, alpha reliabilities were unfortunately lower than desired for openness to experience facets. Nevertheless, reliability values in our sample are similar to 
previous studies using the same openness to experience facets (Allemand, Hill, \& Lehmann, 2015; Chapman, 2007). Further, comparative fit indices for the overall trait models were rather poor compared to models on personality facet level. Thus a cautious interpretation of results on trait level is advised. In order to improve validity and to detect small effects, future studies would benefit from applying more reliable personality questionnaires or observer measures. Second, even though the investigated sample was diverse, it was not nationally representative and probably had more time available for this extensive intervention than others. Third, intervention and control groups only consisted of a young and an old age group. Ideally, one uses a lifespan sample if one wants to generalize across age. Under limited resources it is however very common in research on adult development to work with special groups of younger and older adults, only. Fourth, we only have self-report data on personality which may be biased by social desirability responding. Ideally, self-report is combined with observer methods when assessing personality (Vazire, 2010). Thus, future research on personality trait change in wake of a cognitive training would surely benefit from taking observer reports into account. A fifth limitation of the present study is that we did not assess personality traits immediately after the cognitive training phase, but two years later. Thus, we do not know whether participants changed in openness to experience or other personality traits in short-term or not.

Future studies should compare the short-term and long-term effects of different kinds of cognitive training on openness to experience and reinvestigate the surprising negative influence of cognitive training on conscientiousness that we found. Additionally, all potential boundary conditions to cognitive training effects on openness change carved out here need further investigation and systematical testing. 


\section{Conclusion}

This study has identified that, other than tentatively expected, even an extensive cognitive training of episodic memory, working memory, and perceptual speed does not serve as a sufficient intervention for enduring long-term changes in openness to experiences or one of its facets. Our results highlight the relevance of cognitive training type and time frame when investigating cognitive training interventions as a context for change in openness to experience and other personality traits. 


\section{Declaration of Conflicting Interests}

The author(s) declared no potential conflicts of interest with respect to the research, authorship, and/or publication of this article.

\section{Funding}

The author(s) disclosed receipt of the following financial support for the research, authorship, and/or publication of this article: The COGITO Study was supported by the Max Planck Society, including a grant from the innovation fund of the Max Planck Society (M.FE.A.BILD0005) and the Sofja Kovalevskaja Award (to Martin Lövdén) of the Alexander von Humboldt Foundation donated by the German Federal Ministry for Education and Research (BMBF); the German Research Foundation (DFG; KFG 163); and the BMBF (CAI).

Preparation of this article was supported by a stipend from the German Institute for Economic Research (DIW Berlin), Berlin, Germany awarded to Julia Sander. 
References

Ackerman, P. L. \& Heggestad, E. D. (1997). Intelligence, personality, and interests: Evidence for overlapping traits. Psychological Bulletin, 121, 219-245. doi:10.1037//00332909.121.2.219

Allemand, M., Hill, P. L., \& Lehmann, R. (2015). Divorce and personality development across middle adulthood. Personal Relationships, 22, 122-137. doi:10.1111/pere.12067

Baltes, P. B. (1997). On the incomplete architecture of human ontogeny: Selection, Optimization, and Compensation as Foundation of Developmental Theory. American Psychologist, 52, 366-380. doi:10.1037/0003-066X.52.4.366

Baltes, P. B., Lindenberger, U., \& Staudinger, U. M. (2006). Life span theory in developmental psychology. In W. Damon \& R. M. Lerner (Eds.), Handbook of child psychology: Vol. 1. Theoretical models of human development (6th ed., pp. 569-664). New York: Wiley.

Bleidorn, W., Kandler, C., Riemann, R., Angleitner, A., \& Spinath, F. M. (2009). Patterns and sources of adult personality development: Growth curve analyses of the NEO-PI-R scales in a longitudinal twin study. Journal of Personality and Social Psychology, 97, 142-155. doi:10.1037/a0015434

Chapman, B. P. (2007). Bandwidth and fidelity on the NEO Five-Factor Inventory: replicability and reliability of Saucier's (1998) item cluster subcomponents. Journal of Personality Assessment, 88, 220-34. doi:10.1080/00223890701268082

Chapman, B. P., Hampson, S., \& Clarkin, J. (2014). Personality-informed prevention and intervention for healthy aging. Developmental Psychology, 50, 1426-1441. doi:10.1037/a0034135. 
Costa P.T., \& McCrae R.R. (1992) Revised NEO personality inventory (NEO-PI-R) and NEO five factor inventory (NEO-FFI) professional manual. Odessa, FL: Psychological Assessment Resources.

Depthlink, Inc. (2015). NiceIQ - Brain Training (Version 1.68) [Mobile application software]. Retrieved from https://play.google.com/store/apps/details?id=com.depthlink.brain

Dittmann-Kohli, F., Lachmann, M.E., Kliegl,R. \& Baltes, P.B. (1991). Effects of cognitive training and testing on intellectual efficacy beliefs in elderly adults. Journal of Gerontology, 46, 162-164. doi:10.1093/geronj/46.4.P162

Edlogiq. (2014). Neuron Gym: Brain Trainer Beta (Version 1.11) [Mobile application software]. Retrieved from https://play.google.com/store/apps/details?id=com.edlogiq.neurongym

Enders, C. K., \& Bandalos, D. L. (2001). The relative performance of full information maximum likelihood estimation for missing data in structural equation models. Structural Equation Modeling, 8, 430-457.doi:10.1207/S15328007SEM0803_5

Hu, L. T., \& Bentler, P. M. (1998). Fit indices in covariance structure modeling: Sensitivity to under parameterized model misspecification. Psychological Methods, 3, 424-453. doi:10.1037/1082-989X.3.4.424

Hudson, N. W., \& Fraley, R. C. (2015). Volitional Personality Trait Change: Can People Choose to Change Their Personality Traits?. Journal of Personality and Social Psychology, 109, 490-507. doi:10.1037/pspp0000021

Jackson, J. J., Hill, P. L., Payne, B. R., Roberts, B. W., \& Stine-Morrow, E. A. (2012). Can an old dog learn (and want to experience) new tricks? Cognitive training increases openness to experience in older adults. Psychology and Aging, 27, 286 - 292. doi:10.1037/a0025918

John, O. P., Naumann, L. P., \& Soto, C. J. (2008). Paradigm Shift to the Integrative Big-Five Trait Taxonomy: History, Measurement, and Conceptual Issues. In O. P. John, R. W. 
Robins, \& L. A. Pervin (Eds.), Handbook of personality: Theory and research (3rd ed., pp. 114-158). New York: Guilford Press.

Lucas, R. E., \& Donnellan, M. B. (2011). Personality development across the life span: Longitudinal analyses with a national sample from Germany. Journal of Personality and Social Psychology, 101, 847-861. doi:10.1037/a0024298

Magidson, J. F., Roberts, B. W., Collado-Rodriguez, A., \& Lejuez, C. W. (2012). TheoryDriven Intervention for Changing Personality: Expectancy Value Theory, Behavioral Activation, and Conscientiousness. Developmental Psychology. Advance online publication. doi: 10.1037/a0030583

Marsh, H. W., Hau, K.-T., \& Grayson, D. (2005). Goodness of fit evaluation in structural equation modeling. In A. Maydeu-Olivares \& J. McCardle (Eds.), Contemporary psychometrics: A Festschrift to Roderick P. McDonald (pp. 275-340). Mahwah, NJ: Erlbaum.

Marsh, H. W., Nagengast, B.; Morin, A. (2013). Measurement Invariance of Big-Five Factors Over the Life Span: ESEM Tests of Gender, Age, Plasticity, Maturity, and La Dolce Vita Effects. Developmental Psychology, 49, 1194-1218. doi: 10.1037/a0026913

McArdle, J. J. (2009). Latent variable modelling of differences and changes with longitudinal data. Annual Review of Psychology, 60, 577-605.

doi:10.1146/annurev.psych.60.110707.163612

McCrae, R. R., \& Sutin, A. R. (2009). Openness to Experience. In M. R. Leary \& R. H. Hoyle (Eds.), Handbook of Individual Differences in Social Behavior (pp. 257-273). New York: Guilford.

Muthén, L.K. and Muthén, B.O. (1998-2012). Mplus User's Guide. Seventh Edition. Los Angeles, CA: Muthén \& Muthén. 
Peters, A.-L. (2015). Goals to change oneself: A state and trait perspective on self-regulated personality development in adulthood. (Unpublished doctoral dissertation), Bielefeld University, Germany.

Roberts, B. W., \& DelVecchio, W. F. (2000). The rank-order consistency of personality traits from childhood to old age: A quantitative review of longitudinal studies. Psychological Bulletin, 126, 3-25. doi:10.1037/0033-2909.126.1.3

Roberts, B. W., \& Jackson, J. J. (2008). Sociogenomic personality psychology. Journal of Personality, 76, 1523-1544. doi:10.1111/j.1467-6494.2008.00530.x.

Roberts, B. W., Walton, K. E., \& Viechtbauer, W. (2006). Patterns of Mean-Level Change in Personality Traits across the Life Course: A Meta-Analysis of Longitudinal Studies. Psychological Bulletin, 132, 1-25. doi:10.1037/0033-2909.132.1.1

Roberts, B.W., Wood, D, \& Caspi, A. (2008). The development of personality traits in adulthood. In O.P. John, R.W. Robins, \& L. A. Pervin (Eds.), Handbook of personality: theory and research (3rd ed., pp. 375-398). New York: Guilford.

Saucier, G. (1998) Replicable Item-Cluster Subcomponents in the NEO Five-Factor Inventory, Journal of Personality Assessment, 70, 263-276, doi:10.1207/s15327752jpa7002_6

Schmiedek, F., Lövdén, M., \& Lindenberger, U. (2010). Hundred days of cognitive training enhance broad cognitive abilities in adulthood: Findings from the COGITO study. Frontiers in Aging Neuroscience, 2, 27. doi:10.3389/fnagi.2010.00027

Schmiedek, F., Lövdén, M., \& Lindenberger, U. (2014). Younger adults show long-term effects of cognitive training on broad cognitive abilities over two years. Developmental Psychology, 50, 2304-2310. doi:10.1037/a0037388 
Schmiedek, F., Bauer, C., Lövdén, M., Brose, A., \& Lindenberger, U. (2010). Cognitive enrichment in old age: web-based training programs. GeroPsych, 23, 59-67. doi:10.1024/1662-9647/a000013

Specht, J., Bleidorn, W., Denissen, J. J. A., Hennecke, M., Hutteman, R., Kandler, C., Luhmann, M., Orth, U., Reitz, A. K., \& Zimmermann, J. (2014). What drives adult personality development? A comparison of theoretical perspectives and empirical evidence. European Journal of Personality, 28, 216-230. doi:10.1002/per.1966

Specht, J., Egloff, B. \& Schmukle, S. C. (2011). Stability and change of personality across the life course: The impact of age and major life events on mean-level and rank-order stability of the Big Five. Journal of Personality and Social Psychology, 101, 862-882. doi:10.1037/a002495

Specht, J., Luhmann, M. \& Geiser, C. (2014). On the consistency of personality types across adulthood: Latent profile analyses in two large-scale panel studies. Journal of Personality and Social Psychology, 107, 540-556. doi:10.1037/a0036863

van de Schoot, R., Lugtig P. \& Hox, J. (2012). A checklist for testing measurement invariance, European Journal of Developmental Psychology, 9, 486-492, doi:10.1080/17405629.2012.686740

Vazire. S. (2010). Who knows what about a person? The Self-Other Knowledge Asymmetry (SOKA) model. Journal of Personality and Social Psychology, 98, 281-300. doi:10.1037/a0017908

Vivity Labs (2015). Fit Brains (Gehirn-Fitness) (Version 1.1.2) [Mobile application software]. Retrieved from https://play.google.com/store/apps/details?id=com.vivitylabs.android.braintrainer 


\section{Footnotes}

${ }^{1}$ Including the omitted openness to experience item leads to a significant lower trait mean in the sample at pretest $(M=2.62, S D=0.49, p<0.01)$; Cronbach's alpha $=0.70$ was of similar size. Including the omitted extraversion item also leads to a significant lower trait mean at pretest in the sample $(M=2.27, S D=0.49, p<0.001)$; Cronbach's alpha $\alpha=0.79$ was slightly smaller. The pattern of results in the latent change models did not change when adding these items, except for model fit indices being lower.

${ }^{2}$ We standardized all model parameters using the square root of the estimated variance of the latent intercept. 


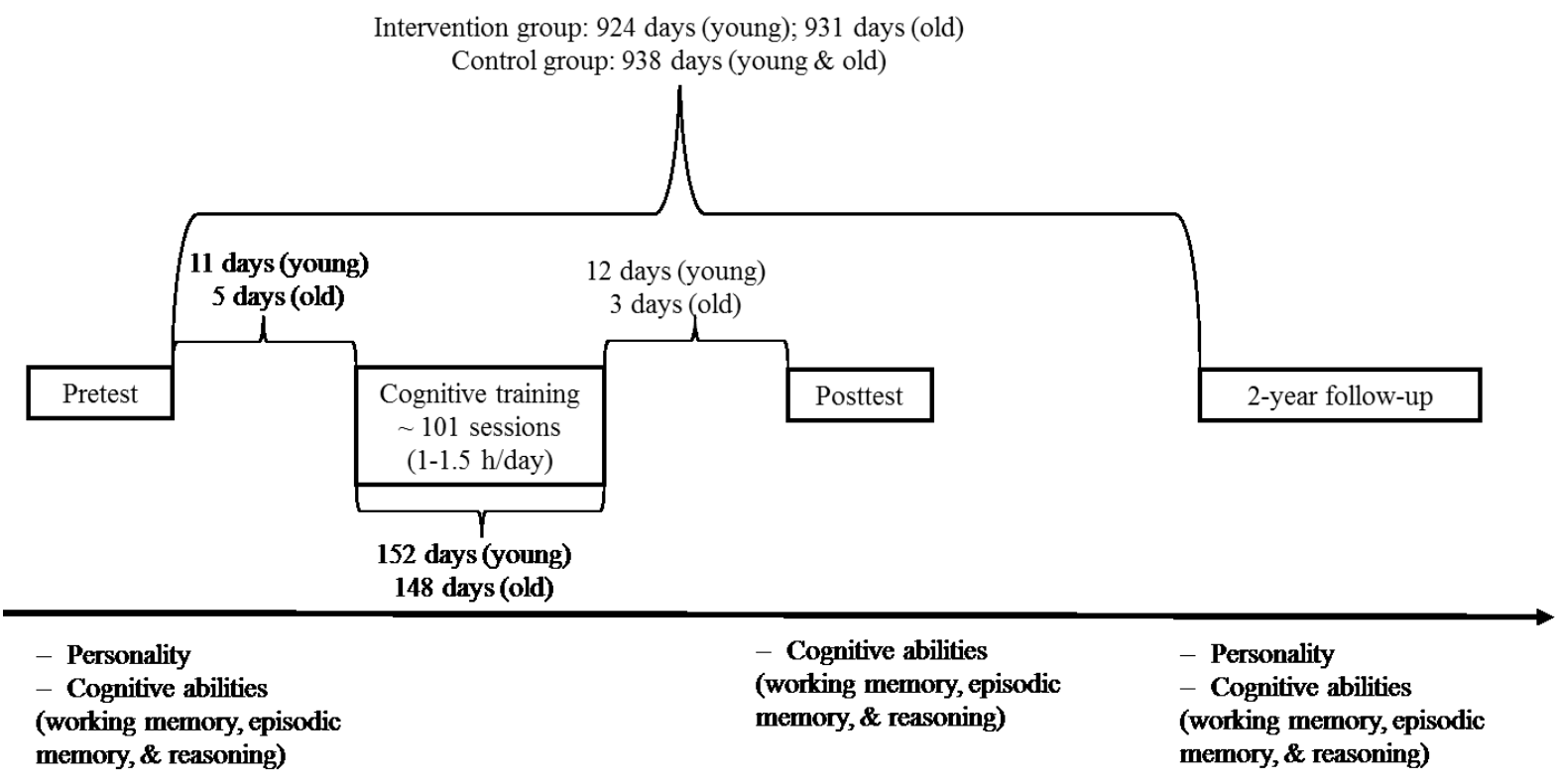

Figure 1. Timeline of COGITO study with median time intervals in days. For details on cognitive training content, personality assessment, cognitive abilities assessment see method section, Schmiedek, Bauer, Lövdén, Brose, \& Lindenberger, (2010), and Schmiedek, Lövdén, \& Lindenberger, (2010). 
PERSONALITY DEVELOPMENT AND COGNITIVE TRAINING

Table 1

Descriptive Statistics of Saucier's Personality Facets in the Full Sample at Pretest

\begin{tabular}{lccccc}
\hline Big Five & $N$ & $M$ & $S D$ & $\begin{array}{c}\text { Number } \\
\text { of Items }\end{array}$ & $\begin{array}{c}\text { Cronbach's } \\
\text { Alpha }\end{array}$ \\
\multicolumn{1}{c}{ Personality Facets } & & & & & \\
\hline Openness & 282 & 2.63 & 0.52 & 9 & 0.72 \\
$\quad$ Intellectual Interests & 286 & 2.76 & 0.61 & 3 & 0.47 \\
Unconventionality & 284 & 2.36 & 0.69 & 3 & 0.37 \\
Aesthetic Interests & 287 & 2.79 & 0.67 & 3 & 0.64 \\
& & & & & \\
Extraversion & 280 & 2.34 & 0.52 & 11 & 0.81 \\
$\quad$ Positive Affect & 287 & 2.67 & 0.72 & 4 & 0.82 \\
$\quad$ Sociability & 286 & 2.17 & 0.61 & 4 & 0.63 \\
Activity & 285 & 2.12 & 0.61 & 3 & 0.55 \\
& & & & & \\
Emotional Stability & 284 & 2.34 & 0.60 & 12 & 0.84 \\
$\quad$ (no) Self Reproach & 284 & 2.40 & 0.65 & 7 & 0.79 \\
$\quad$ (no) Negative Affect & 286 & 2.26 & 0.67 & 5 & 0.65 \\
& & & & & \\
Conscientiousness & 282 & 2.53 & 0.56 & 12 & 0.85 \\
Dependability & 285 & 2.73 & 0.58 & 4 & 0.70 \\
Goal Striving & 288 & 2.47 & 0.66 & 3 & 0.68 \\
Orderliness & 284 & 2.41 & 0.73 & 5 & 0.77 \\
& & & & & \\
Agreeableness & 283 & 2.57 & 0.40 & 12 & 0.69 \\
Non-antagonistic orientation & 2.41 & 0.46 & 8 & 0.57 \\
Pro-social orientation & 2.89 & 0.46 & 4 & 0.56 \\
\hline
\end{tabular}

Note. Scales range from 0 (strongly disagree) to 4 (strongly agree).

${ }^{a}$ We excluded two items because they did load inappropriately (negative) on their personality trait in our sample at post-test (see main text for further information). 


\section{PERSONALITY DEVELOPMENT AND COGNITIVE TRAINING}

Table 2

Information on Model Fit Indices for Latent Change Models (LCM) with Covariates, and Effects on Intercepts of Models that include Training, Age group, and Gender as Covariates ${ }^{a}$

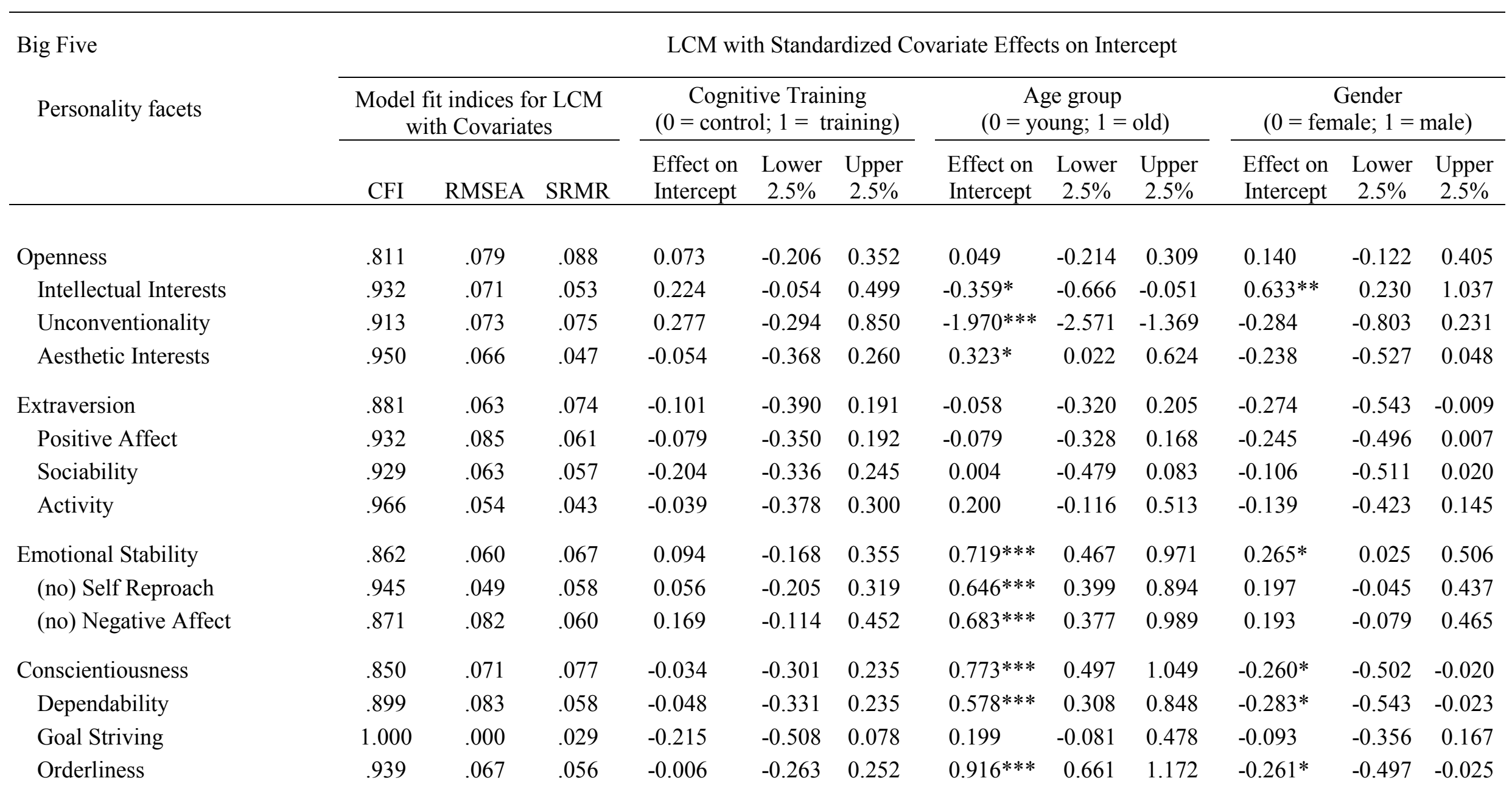




\section{PERSONALITY DEVELOPMENT AND COGNITIVE TRAINING}

\begin{tabular}{|c|c|c|c|c|c|c|c|c|c|c|c|c|}
\hline Agreeableness & .822 & .059 & .073 & 0.038 & -0.246 & 0.323 & $0.528 * *$ & 0.226 & 0.830 & $-0.628 * * *$ & -0.930 & -0.326 \\
\hline
\end{tabular}

Note. All model parameters are standardized using the square root of the estimated variance of the latent intercept. LCM $=$ latent change model; CFI $=$ Comparative fit index;

RMSEA $=$ Root mean square error of approximation; SRMR $=$ Standardized root mean square residual; Lower $2.5 \%=$ lower bound of $95 \%$-confidence interval; Upper $2.5 \%=$

upper bound of $95 \%$-confidence interval; $* p<.05 . * p<.01 ; * * p<.001$

${ }^{a}$ Means of intercept factors in latent change models for the control group only are set to zero by default. 


\section{PERSONALITY DEVELOPMENT AND COGNITIVE TRAINING}

Table 3

Information on the Slopes of the Latent Change Models (LCM) for the Control Group without any Covariates, and Effects on Slopes of Models that include Cognitive Training, Age group, and Gender as Covariates

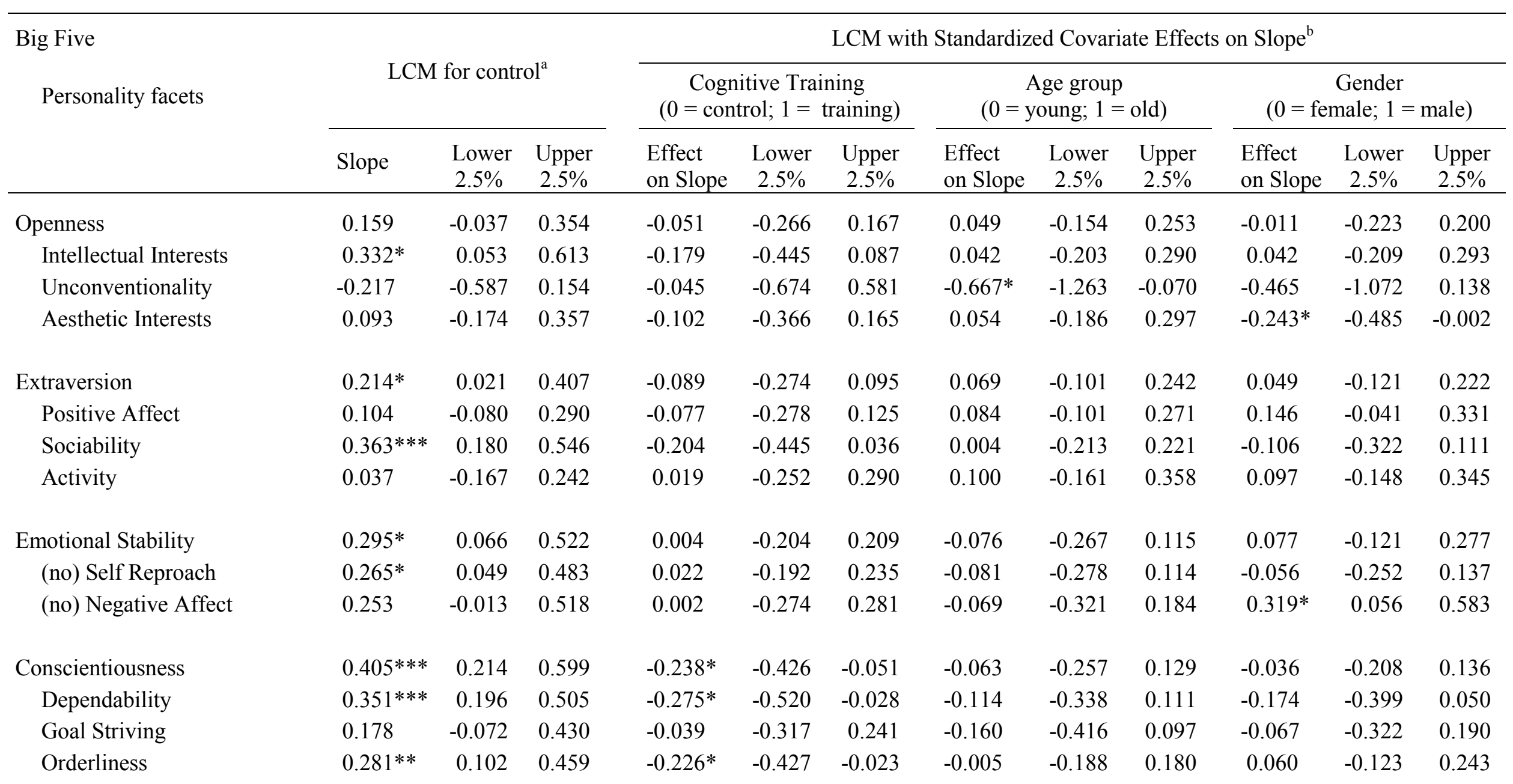




\section{PERSONALITY DEVELOPMENT AND COGNITIVE TRAINING}

\begin{tabular}{|c|c|c|c|c|c|c|c|c|c|c|c|c|}
\hline Agreeableness & 0.114 & -0.090 & 0.315 & 0.184 & -0.052 & 0.420 & -0.163 & -0.385 & 0.059 & 0.080 & -0.139 & 0.299 \\
\hline
\end{tabular}

Note. All model parameters are standardized using the square root of the estimated variance of the latent intercept. LCM = latent change model; CFI = Comparative fit index;

RMSEA $=$ Root mean square error of approximation; SRMR $=$ Standardized root mean square residual; Lower $2.5 \%=$ lower bound of $95 \%$-confidence interval; Upper $2.5 \%=$ upper bound of $95 \%$-confidence interval; $* p<.05 . * * p<.01 ; * * p<.001$

${ }^{a}$ For information on model fit indices of latent change models for control group, please see main text.

${ }^{\mathrm{b}}$ For model fit indices of LCM with covariates please see Table 2. 


\section{PERSONALITY DEVELOPMENT AND COGNITIVE TRAINING}

S1

Information on Model Fit Indices for Latent Change Models (LCM) with Covariates, and Unstandardized Effects on Intercepts of Models that include Training, Age group, and Gender as Covariates ${ }^{a}$

\begin{tabular}{|c|c|c|c|c|c|c|c|c|c|}
\hline \multirow{3}{*}{$\begin{array}{l}\text { Big Five } \\
\text { Personality facets }\end{array}$} & \multicolumn{9}{|c|}{ LCM with Unstandardized Covariate Effects on Intercept ${ }^{\mathrm{b}}$} \\
\hline & \multicolumn{3}{|c|}{$\begin{array}{c}\text { Cognitive Training } \\
(0=\text { control } ; 1=\text { training })\end{array}$} & \multicolumn{3}{|c|}{$\begin{array}{c}\text { Age group } \\
(0=\text { young; } 1=\text { old })\end{array}$} & \multicolumn{3}{|c|}{$\begin{array}{c}\text { Gender } \\
(0=\text { female; } 1=\text { male })\end{array}$} \\
\hline & $\mathrm{b}$ & $\begin{array}{c}\text { Lower } \\
2.5 \%\end{array}$ & $\begin{array}{c}\text { Upper } \\
2.5 \%\end{array}$ & $\mathrm{~b}$ & $\begin{array}{c}\text { Lower } \\
2.5 \%\end{array}$ & $\begin{array}{c}\text { Upper } \\
2.5 \%\end{array}$ & $\mathrm{~b}$ & $\begin{array}{c}\text { Lower } \\
2.5 \%\end{array}$ & $\begin{array}{c}\text { Upper } \\
2.5 \%\end{array}$ \\
\hline Openness & 0.039 & -0.110 & 0.188 & 0.026 & -0.114 & 0.165 & 0.075 & -0.065 & 0.216 \\
\hline Intellectual Interests & 0.075 & -0.018 & 0.167 & $-0.120^{*}$ & -0.223 & -0.017 & $0.212^{* *}$ & 0.077 & 0.347 \\
\hline Unconventionality & 0.110 & -0.117 & 0.338 & $-0.783 * * *$ & -1.022 & -0.544 & -0.113 & -0.319 & 0.092 \\
\hline Aesthetic Interests & -0.025 & -0.170 & 0.120 & $0.149^{*}$ & 0.010 & 0.288 & -0.110 & -0.243 & 0.022 \\
\hline Extraversion & -0.035 & -0.135 & 0.066 & -0.020 & -0.111 & 0.071 & $-0.095^{*}$ & -0.188 & -0.003 \\
\hline Positive Affect & -0.033 & -0.146 & 0.080 & -0.033 & -0.137 & 0.070 & -0.102 & -0.207 & 0.003 \\
\hline Sociability & -0.154 & -0.254 & 0.185 & 0.003 & -0.362 & 0.063 & -0.080 & -0.386 & 0.015 \\
\hline Activity & -0.012 & -0.117 & 0.093 & 0.062 & -0.036 & 0.159 & -0.043 & -0.131 & 0.045 \\
\hline
\end{tabular}




\section{PERSONALITY DEVELOPMENT AND COGNITIVE TRAINING}

\begin{tabular}{|c|c|c|c|c|c|c|c|c|c|}
\hline Emotional Stability & 0.052 & -0.093 & 0.197 & $0.399 * * *$ & 0.259 & 0.539 & $0.147^{*}$ & 0.014 & 0.281 \\
\hline (no) Self Reproach & 0.034 & -0.124 & 0.193 & $0.390 * * *$ & 0.241 & 0.540 & 0.119 & -0.027 & 0.264 \\
\hline (no) Negative Affect & 0.079 & -0.053 & 0.211 & $0.319 * * *$ & 0.176 & 0.462 & 0.090 & -0.037 & 0.217 \\
\hline Conscientiousness & -0.020 & -0.177 & 0.138 & $0.454 * * *$ & 0.292 & 0.616 & $-0.153^{*}$ & -0.295 & -0.012 \\
\hline Dependability & -0.019 & -0.131 & 0.093 & $0.229 * * *$ & 0.122 & 0.336 & $-0.112^{*}$ & -0.215 & -0.009 \\
\hline Goal Striving & -0.122 & -0.288 & 0.044 & 0.113 & -0.046 & 0.271 & -0.053 & -0.202 & 0.095 \\
\hline Orderliness & -0.004 & -0.171 & 0.164 & $0.596 * * *$ & 0.430 & 0.762 & $-0.170^{*}$ & -0.323 & -0.016 \\
\hline Agreeableness & 0.011 & -0.071 & 0.093 & $0.152 * *$ & 0.065 & 0.239 & $-0.181 * * *$ & -0.268 & -0.094 \\
\hline Non-antagonistic orientation & 0.040 & -0.049 & 0.129 & $0.144 * *$ & 0.050 & 0.239 & $-0.161 * *$ & -0.252 & -0.070 \\
\hline Pro-social orientation & -0.028 & -0.154 & 0.099 & $0.181 * *$ & 0.064 & 0.299 & $-0.208 * *$ & -0.326 & -0.090 \\
\hline
\end{tabular}

Note. $\mathrm{LCM}=$ latent change model; $\mathrm{CFI}=$ Comparative fit index; RMSEA = Root mean square error of approximation; SRMR = Standardized root mean square residual; Lower $2.5 \%=$ lower bound of $95 \%$-confidence interval; Upper $2.5 \%=$ upper bound of $95 \%$-confidence interval; *p<.05;**p<.01;*** $<<.001$.

${ }^{a}$ Means of intercept factors are set to zero in the control group.

${ }^{\mathrm{b}}$ Model fit indices are given in Table 2. 


\section{PERSONALITY DEVELOPMENT AND COGNITIVE TRAINING}

S2

Information on the Unstandardized Slopes of the Latent Change Models (LCM) for the Control Group without any Covariates, and Unstandardized Effects on Slopes of Models that include Cognitive Training, Age group, and Gender as Covariates

\begin{tabular}{|c|c|c|c|c|c|c|c|c|c|c|c|c|}
\hline \multirow{3}{*}{$\begin{array}{l}\text { Big Five } \\
\text { Personality facets }\end{array}$} & & & & \multicolumn{9}{|c|}{ LCM with Unstandardized Covariate Effects on Slope ${ }^{b}$} \\
\hline & \multicolumn{3}{|c|}{$\mathrm{LCM}_{\text {for }}$ control $^{\mathrm{a}}$} & \multicolumn{3}{|c|}{$\begin{array}{c}\text { Cognitive Training } \\
(0=\text { control; } 1=\text { training })\end{array}$} & \multicolumn{3}{|c|}{$\begin{array}{c}\text { Age group } \\
(0=\text { young; } 1=\text { old })\end{array}$} & \multicolumn{3}{|c|}{$\begin{array}{c}\text { Gender } \\
(0=\text { female } ; 1=\text { male })\end{array}$} \\
\hline & Slope & $\begin{array}{c}\text { Lower } \\
2.5 \%\end{array}$ & $\begin{array}{c}\text { Upper } \\
2.5 \%\end{array}$ & $\mathrm{~b}$ & $\begin{array}{c}\text { Lower } \\
2.5 \%\end{array}$ & $\begin{array}{c}\text { Upper } \\
2.5 \%\end{array}$ & $\mathrm{~b}$ & $\begin{array}{c}\text { Lower } \\
2.5 \%\end{array}$ & $\begin{array}{c}\text { Upper } \\
2.5 \%\end{array}$ & $\mathrm{~b}$ & $\begin{array}{c}\text { Lower } \\
2.5 \%\end{array}$ & $\begin{array}{l}\text { Upper } \\
2.5 \%\end{array}$ \\
\hline Openness & 0.082 & -0.019 & 0.183 & -0.027 & -0.142 & 0.089 & 0.026 & -0.082 & 0.135 & -0.006 & -0.119 & 0.107 \\
\hline Intellectual Interests & $0.144^{*}$ & 0.023 & 0.266 & -0.060 & -0.149 & 0.029 & 0.014 & -0.068 & 0.097 & 0.014 & -0.070 & 0.098 \\
\hline Unconventionality & -0.120 & -0.324 & 0.085 & -0.018 & -0.268 & 0.231 & $-0.265^{*}$ & -0.502 & -0.028 & -0.185 & -0.426 & 0.055 \\
\hline Aesthetic Interests & 0.037 & -0.069 & 0.142 & -0.047 & -0.169 & 0.076 & 0.025 & -0.086 & 0.137 & $-0.112 *$ & -0.224 & -0.001 \\
\hline Extraversion & $0.070^{*}$ & 0.007 & 0.133 & -0.031 & -0.095 & 0.033 & 0.024 & -0.035 & 0.084 & 0.017 & -0.042 & 0.077 \\
\hline Positive Affect & 0.043 & -0.033 & 0.120 & -0.032 & -0.116 & 0.052 & 0.035 & -0.042 & 0.113 & 0.061 & -0.017 & 0.138 \\
\hline Sociability & $0.351 * * *$ & 0.174 & 0.528 & -0.154 & -0.336 & 0.027 & 0.003 & -0.161 & 0.167 & -0.080 & -0.243 & 0.084 \\
\hline Activity & 0.006 & -0.027 & 0.039 & 0.006 & -0.078 & 0.090 & 0.031 & -0.050 & 0.111 & 0.030 & -0.046 & 0.107 \\
\hline
\end{tabular}




\section{PERSONALITY DEVELOPMENT AND COGNITIVE TRAINING}

\begin{tabular}{|c|c|c|c|c|c|c|c|c|c|c|c|c|}
\hline Emotional Stability & $0.143 *$ & 0.032 & 0.253 & 0.002 & -0.113 & 0.116 & -0.042 & -0.148 & 0.064 & 0.043 & -0.067 & 0.154 \\
\hline (no) Self Reproach & $0.145^{*}$ & 0.027 & 0.264 & 0.013 & -0.116 & 0.142 & -0.049 & -0.168 & 0.069 & -0.034 & -0.152 & 0.083 \\
\hline (no) Negative Affect & 0.160 & -0.008 & 0.328 & 0.001 & -0.128 & 0.131 & -0.032 & -0.150 & 0.086 & $0.149 *$ & 0.026 & 0.272 \\
\hline Conscientiousness & $0.235 * * *$ & 0.124 & 0.347 & $-0.140^{*}$ & -0.250 & -0.030 & -0.037 & -0.151 & 0.076 & -0.021 & -0.122 & 0.080 \\
\hline Goal Striving & 0.092 & -0.037 & 0.222 & -0.022 & -0.180 & 0.137 & -0.091 & -0.236 & 0.055 & -0.038 & -0.183 & 0.108 \\
\hline Orderliness & $0.200 * *$ & 0.073 & 0.327 & $-0.147 *$ & -0.278 & -0.015 & -0.003 & -0.122 & 0.117 & 0.039 & -0.080 & 0.158 \\
\hline Pro-social orientation & $0.160^{*}$ & 0.023 & 0.298 & 0.003 & -0.127 & 0.133 & -0.047 & -0.168 & 0.073 & 0.064 & -0.055 & 0.182 \\
\hline
\end{tabular}

Note. LCM = latent change model; CFI = Comparative fit index; RMSEA = Root mean square error of approximation; SRMR = Standardized root mean square residual; Lower $2.5 \%=$ lower bound of $95 \%$-confidence interval; Upper $2.5 \%$ = upper bound of $95 \%$-confidence interval; ${ }^{*} p<.05 . * * p<.01 ;{ }^{* * *} p<.001$;

${ }^{a}$ Model fit indices are given in the main text.

${ }^{\mathrm{b}}$ Model fit indices are given in Table 2 . 